\title{
Динамика рекомбинации и спиновой релаксации экситонов в гетероструктурах (II,Al)(As,Sb)/AlAs
}

\author{
Т.С. Шамирзаев ${ }^{1}$, А.К. Бакаров ${ }^{1}$, Д.Р. Яковлев ${ }^{2}$, M. Bayer $^{2}$ \\ ${ }^{1}$ ИФП СО РАН, 630090, Новосибирск, пр. Ак. Лаврентьева, 13 \\ ${ }^{2}$ TechnischeUniversität Dortmund, D-44221 Dortmund, Germany, Otto-Hahn-Strasse 4a
}

DOI 10.34077/RCSP2021-119

Для изучения спиновой динамики спиновую систему, необходимо вывести из равновесия и создать неравновесную заселенность спиновых состояний. Удобным методом для создания неравновесной спиновой заселенности является нерезонансное возбуждение неполяризованным светом расщепленных продольным магнитным полем состояний экситонов. При больших (по сравнению с термической энергией $\mathrm{kT}$ ) величинах Зеемановского расщепления (Ez) одинаковая заселенность экситонных состояний с различными проекциями спина, обеспечивающаяся при таком возбуждении, соответствует термодинамически неравновесному распределению. С течением времени процессы спиновой релаксации, стремятся привести заселенности экситонных состояний в соответствие с равновесным (больцмановским) распределением. Стремление спиновой системы к равновесию сопровождается появлением циркулярной поляризации фотолюминесценции (ФЛ). Для типичных структур с КТ при условии Ez >> kT максимальная степень поляризации ФЛ определяется отношением времени жизни экситона (tr) к времени спиновой релаксации (ts) и при условии $\operatorname{tr}>$ ts стремится к $100 \%[1]$.

В работе показано, что в непрямозонных гетеростурктурах (In, $\mathrm{Al})(\mathrm{Sb}, \mathrm{As}) / \mathrm{AlAs}$ и $\mathrm{Al}(\mathrm{Sb}, \mathrm{As}) / \mathrm{AlAs}$ не смотря на выполнение условия $\mathrm{Ez} \gg \mathrm{kT}$ и большие времена $\operatorname{tr}$ (сотни микросекунд), заметно превышающие типичные времена спиновой релаксации электронов и дырок в подобных системах (десятки микросекунд) [2], наведенная магнитным полем циркулярная поляризация ФЛ (МЦП) сильно меняется от образца к образцу, и, неожиданно, меняет знак. Определены значения продольного g фактора тяжелой дырки, а также времена спиновой релаксации электрона и тяжелой дырки, не превышающие 100 нс. Степень наведенной магнитным полем циркулярной поляризации ФЛ подавлена, т.е. заметно меньше, чем для тонких КЯ, реализованных в близкой гетеросистеме GaAs/AlAs [2].

Работа выполнена при финансовой поддержке Deutsche Forschungsgemeinschaft via the Project No. 409810106 и РФФИ (проекты № 19-02-00098 и 19-52-12001).

\section{Лuтература}

[1] Т.С. Шамирзаев, ФТТ 60, 1542 (2018).

[2] T.S. Shamirzaev et al, Phys. Rev. B 96, 035302 (2017). 